\title{
ЭНДОТЕЛИАЛЬНАЯ ДИСФУНКЦИЯ И ЕЕ РОЛЬ В РАЗВИТИИ ПЕЧЕНОЧНОЙ НЕДОСТАТОЧНОСТИ ПРИ МЕХАНИЧЕСКОЙ ЖЕЛТУХЕ
}

\section{ENDOTHELIAL DYSFUNCTION AND ITS ROLE IN THE DEVELOPMENT OF HEPATIC INSUFFICIENCY WITH MECHANICAL JAUNDI}

K. Magomedov

Summary. The review discusses in detail current issues on the issue of liver failure in obstructive jaundice, especially topical issues on the pathogenesis and role of endothelial dysfunction. Domestic and foreign authors in their studies confirm the key role of endothelium in the regulation of vascular hemostasis. The role of endothelium is the development of factors of inflammation and proliferation of vessels, participation in thrombosis and the balance between vasoconstriction and vasodilation. Endothelial dysfunction and damage in obstructive jaundice is manifested by a decrease in the concentration of nitric oxide in the blood, a sharp increase in the content of endothelin-1, the activity of the Wilibrand factor and a decrease in the number of desquamated endotheliocytes. The presence of hemolymphatic changes in endothelial dysfunction is one of the reasons for the development of liver failure, which is necessary for the early diagnosis of obstructive jaundice.

In studies of domestic and foreign authors, there is no data on the role of endothelial dysfunction in the development of liver failure in obstructive jaundice. The identification of markers of endothelial dysfunction and their complications in obstructive jaundice is of great practical importance, as it allows an early diagnosis of liver failure.

The purpose of this review is to present a generalized picture of recent advances devoted to the study of endothelial dysfunction, oxidative stress and the study of their role in endothelial dysfunction, oxidative stress in the pathogenesis of liver failure in obstructive jaundice.

Keywords: endothelial dysfunction, oxidative stress, nitric oxide, obstructive jaundice, liver failure.

\author{
Магомедов Хасае Магомедалиевич \\ Ассистент, Дагестанский государственный \\ медицинский университет \\ hasai2014@mail.ru
}

Аннотация. В обзоре подробно рассмотрены современные проблемы по вопросу печеночной недостаточности при механической желтухе, особо актуальные вопросы по патогенезу и роли эндотелиальной дисфункции. Отечественные и зарубежные авторы в своих исследованиях подтверждают ключевую роль эндотелия в регуляции сосудистого гемостаза. Роль эндотелия заключается в выработке факторов воспаления и пролиферации сосудов, участии в тромбообразовании и балансе между вазоконстрикцией и вазодилятацией. Дисфункция и повреждение эндотелия при механической желтухе, проявляется снижением концентрации в крови оксида азота, резким повышением содержания эндотелина-1, активностью фактора Вилибранда и снижением количества десквамированных эндотелиоцитов. Наличие гемолимфатических изменений при эндотелиальной дисфункции является одной из причин развития печеночной недостаточности, что и необходимо для ранней диагностики механической желтухи.

В исследованиях отечественных и зарубежных авторов нет данных о роли дисфункции эндотелия в развитии печеночной недостаточности при механической желтухе. Определение маркеров эндотелиальной дисфункции и их осложнения при механической желтухе имеет большое практическое значение, так как позволяет провести раннюю диагностику печеночной недостаточности.

Цель настоящего обзора заключается в представлении обобщенной картины последних достижений, посвященных изучению эндотелиальной дисфункции, оксидантного стресса и изучению их роли в эндотелиальной дисфункции, оксидантного стресса в патогенезе печеночной недостаточности при механической желтухе.

Ключевые слова: эндотелиальная дисфункция, оксидантный стресс, оксид азота, механическая желтуха, печеночная недостаточность.

чаше нарушается при механической желтухе. К синусоидальным клеткам печени относят эндотелиальные клетки синусоидов, звездчатые клетки печени, клетки Купфера, Ріt-клетки, дендритные клетки. Синусоидальные клетки печени составляют около 33\% от клеточного состава печени, при этом доля эндотелиальных клеток синусоидов достигает 70\% [6,29].

При механической желтухе тяжелой формы отмечается нарушение перфузии печени. Внутрипеченочный 
проток находится в сложном взаимодействии между эндотелиальными клетками синусоидов, макрофагами печени, что ведет к снижению скорости кровотока в синусоидах печени. Оксидантный стресс и реперфузионные повреждения микрососудистого русла печени, приводит к дисфункции эндотелиально-клеточного барьера с развитием печеночной недостаточности. При механической желтухе прогрессивное ухудшение печеночной недостаточности происходит за счет развития тромбогенности сосудистой стенки при эндотелиальной дисфункции с проявлением оксидантного стресса $[3,7,21]$. При механической желтухе появление в больших количествах фактора Виллибранда и эндотелина приводит к сосудосуживающему эффекту с нарушением микроциркуляции. Эндотелин в отдельности обладает мощным фактором вазоконстрикции $[9,10,14,33]$.

Развитие эндотелиальной дисфункции имеет прогностическое значение и считается одним из основных маркеров при печеночной недостаточности $[1,3,15]$. В данном исследовании оценены основные показатели взаимосвязи эндотелиальной дисфункции и оксидативного стресса и их влияние на развитии печеночной недостаточности при механической желтухе.

Эндотелий сосудов печени регулирует тонус путем высвобождения ряда вазоконстрикторов и вазодилятаторов, обладает антикоагулянтным, противоагрегантным и фибринолитическим фактором в норме [7,9]. Оксид азота (NO) является фактором релаксации и основным вазодилататором сосудов печени. Роль эндотелия заключается в синтезе оксида азота, простациклина и брадикинина, как факторов вазодилатации $[3,12,16,29]$. Оксид азота и простациклин взаимодействуя между собой ингибирует агрегацию тромбоцитов. Роль брадикинина сводится к стимуляции и высвобождению оксида азота, простациклина и эндотелиального фактора, что способствует подавлению агрегационной способности тромбоцитов [4]. Эндотелин который продуцируется эндотелием сосудов печени является самым мощным фактором вазоконстрикции с ангиотензином II [4,5,19]. Роль ангиотензина II сводится в качестве прооксиданта может выступать в роли и в качестве прооксиданта [3,4,7], потенцирующих экспрессию молекул адгезии и синтез провоспалительных цитокинов $[9,10]$. Внутрипеченочная желчная гипертензия является фактором повреждения эндотелия сосудов печени, что приводит к агрегации тромбоцитов, лейкоцитарной инфильтрации и высвобождению цитокинов с развитием печеночной недостаточности. Важным функциональным показателем является состояние эндотелия и эндотелий зависимая вазодилатация, которая регулируется NO. Снижение синтеза оксида азота эндотелием сосудов печени может проявляться с нарушением вазодилатации, которое приводит к механизму эндотелиальной дисфункции и служит одним из маркеров развития печеночной недостаточности при механической желтухе [3,7]. Итак, изменения кровотока печени зависят от продолжительности механической желтухи, а расширение внутрипеченочных желчных протоков, рост градиента давления, приводит к компрессии гепатоцитов и сосудов портальных трактов, содействуя нарастанию ишемии [2,12]. В ответ на ишемию развивается спазм пре- и посткапилляров. Следствием этого являются снижения объемной скорости кровотока, повышение локального периферического сопротивления и замедление беспрерывного тока крови, которая является основным патологическим звеном нарушения регионарной гемодинамики, начиная из первых дней механической желтухи. Нарастание ишемии втягивает в процесс эндотелий сосудов. Научные исследования показали, что эндотелий не пассивный барьер между кровью и тканями, а активный орган, дисфункция которого является обязательным компонентом практически многих заболеваний [11,15].

Эндотелиальная выстилка регулирует сосудистый тонус, тромбообразование, фибринолиз, адгезию и агрегацию тромбоцитов, пролиферацию и миграцию гладкомышечных клеток сосудистой стенки, адгезию и хемотаксис моноцитов и много других процессов $[4,33]$. Печень содержит большое количество сосудов, стенки которых выстилает эндотелиальний покров. Проводя электронно-микроскопическое обследование, установили, что в зоне паренхимы, которая прилегает к приносящим микрососудам, синусоидная стенка образована беспрерывным не фенестрированным эндотелием с наличием сплошной базальной мембраны.

Вызванная ишемией дисфункция эндотелия приводит к высвобождению ими полипептида - эндотелина-1 $[13,29]$. Сам он является мощным вазоконстриктором [1,21], а точкой прикладывания его есть два типа рецепторов. Считается, что активация эндотелина-а (Эт-а) рецептора приводит вазоконстрикторному действию [33], в то же время, активация Эт-в рецептора оказывает содействие высвобождению оксида азота [34]. Ишемия печени побуждает к рефлекторному выбросу в кровь ацетилхолина, гистамина, норадреналина, брадикинина и других соединений, действие которых рядом с активированными Эт-в-рецепторами оказывает содействие высвобождению эндотелием NO [4,5]. Впервые было показано, что только при наличии эндотелиальных клеток повышение дозы ацетилхолина вызвало релаксацию сосудов, которые подверглись предыдущей констрикции норадреналином [27-36]. При отсутствии эндотелиальных клеток в ответ на ацетилхолин наблюдалась вазоконстрикция или отсутствие релаксации. Это привело к открытию эндотелий релаксирующего фактора, который был идентифицирован как NO [17-20]. NO представляет собой легко проникающий через клеточные мембраны, 
живучий несколько секунд жирорастворимый газ, который образовывается из аминокислоты L-аргинина под действием фермента NO-синтетазы. Именно он имеет регуляторное влияние при дисфункции эндотелия, тормозит регулирующую функцию гладкомышечных клеток, а также предотвращает их пролиферацию и миграцию в субэндотелиальное пространство, замедляет агрегацию тромбоцитов, адгезию тромбоцитов и моноцитов, предотвращает окисление липопротеидов низкой плотности, замедляет синтез провоспалительных цитокинов [2-14].

Ингибирующее влияние NO на функцию лейкоцитов и тромбоцитов имеет большое значение для повреждения, вследствие ишемии - реперфузии, так как агрегация и взаимодействие лейкоцитов с сосудистым эндотелием оказывают содействие развитию данного синдрома $[10,13]$. В дальнейшем гипоксия тканей печени, вызванная дисциркуляторными сдвигами, действием АФК и процессом адгезии форменных элементов крови, приводит к прогрессивному поражению гепатоцитов. Поражение клеток печени оказывает содействие высвобождению большого количества цитокинов и ФНО-а. Причем, особенно активно цитокины продуцируются в печени после порогового накопление АФК в ядре. За этот процесс отвечает специфический ядерный фактор транскрипции NF-k. Белок NF-k связывается с регуляторными генами провоспалительных цитокинов и открывает зоны индукции информативной РНК провоспалительных цитокинов, ФНО-а и пептидов-хемоаттрактанов для нейтрофилов и моноцитов $[10,31]$. Высвободившись в большом количестве цитокины запускают программу миграции лейкоцитов. А индуцированная цитокинами экспрессия Е-селектина на поверхность эндотелия оказывает содействие адгезии нейтрофильных гранулоцитов $[13,14]$. В опытах in vitro показано, что стимуляция эндотелиальных клеток цитокинами индуцируют экспрессию Е-селектина через 4-12 часов, а через 24 часа она заканчивается $[14,23]$. Продукция цитокинов в период реперфузии активируется также в периферической ткани. Излишек свободных радикалов, синтезированных в печени, поступает в периферическое русло, которое стимулирует периферию к синтезу цитокинов, поднимая механизм эндотелий-связующей релаксации периферических сосудов, и еще больше оказывает содействие усилению тканевой гипоксии и сдвигу окислительных процессов. Кроме того, нарушение кровотока по воротной вене приводит к возникновению венозного застоя в кишечнике, а ахолия - к нарушению пищеварения и всасывание.

При продолжительной ишемии способность эндотелиальных клеток высвобождать релаксирующие факторы, в том числе и NO, снижается [21]. Снижение синтеза NO связано с разными причинами: нарушение экспрес- сии и транскрипции NO-синтетазы, ускорение метаболизма NO, снижение доступности запасов L-аргинина, как предшественника NO, или комбинации этих факторов. Одновременно увеличивается образование сосудосуживающих факторов (эндотелина, ангиотензина-II, тромбоксана, простагландина, Н2) [19, 21], поднимая тем самым эндотелиальный баланс сосудистого тонуса резко снижается и приводит к гипоксии тканей печени [16]. Продолжительная ишемия и вызванная им дисфункция эндотелия сосудов печени запускает процессы ремоделирования сосудистой стенки, адгезии и агрегации лейкоцитов, тромбоцитов и моноцитов [10, 22], снижая тем самым микроциркуляцию органа [32].

В состоянии ишемии в гепатоцитах проходит также нарушение водно-электролитного обмена. Перераспределение ионов между клетками и внеклеточным окружением предопределяет рост внутриклеточного осмотического давления и распространение тканевого отека [13]. При нормальных условиях концентрация калия в клетке, в сравнении с экстрацеллюлярной жидкостью, высокая, а натрия - низкая. Этот баланс поддерживается АТФ-энергозамещающей мембраной транспортной системы, так называемым, натриевым насосом. Гипоксия снижает синтез АТФ, которая в конечном результате приводит к нарушению работы натриевого насоса.

В литературе приведенные данные о том, что ксантиноксидаза катализирует окисление около 30 алифатических и ароматических альдегидов, которые оказывают содействие выделению большого количества АФК [13]. В дальнейшем АФК и гидроперикиси липидов включаются в передачу сигнала через клеточную мембрану к ядру, выполняя при этом регулирующую роль в процессах пролиферации, апоптоза, клеточной адгезии, свертывания крови. [9-12]. Проникший в ядро клетки АФК приводят к фрагментации ДНК и разрушению жизненно важных белков клетки. Клетка гибнет путем апоптоза, а продолжительность апоптоза завершается через 3-12 часов. Кроме АФК, в период реперфузии резко повышается уровень продуктов гидролиза мембранных липидов - свободных жирных кислот и продуктов перекисного окисление липидов [13]. Таким образом, сразу после ликвидации билиарной гипертензии увеличивается приток крови к печени, которая приводит к повышению уровня АФК. Последние, проникая в ядро клетки, вызывают их апоптоз или интенсифицируют процессы окислительной деструкции липидов, белков, нуклеиновых кислот и др. Именно эти процессы являются основной причиной цитотоксического влияния на гепатоцит в этот период. Образованные в большом количестве токсичные продукты катаболизма белков и недоокисленные продукты вымываются в системный кровоток, что усиливает эндогенную интоксикацию $[6,9,26]$. Наибольшему разрушительному влиянию свободных ради- 
калов кислорода подвергаются эндотелиоциты [9,12]. Деструкция эндотелиальной выстилки создает все условия к стимуляции адгезии лейкоцитов и других форменных элементов крови, а также создает возможность к первичному поражению гепатоцитов [29]. Процесс адгезии и миграции лейкоцитов передает их краевое положение в сосудистом русле. Многие авторы сравнивают этот процесс с прокаткой клеток крови к эндотелию $[2,6]$. Лейкоциты, осуществляя миграцию к первичным пораженным гепатоцитам, взаимодействуют с клетками эндотелия, активируя их, с последующей экспрессией на их поверхности адгезивних молекул, селективных к соответствующему классу лейкоцитов [26]. Существует три типа адгезивних молекул: Р-селектин, L-селектин и Е-селектин [27]. Р-селектин находится в эритроцитах, а его выход и экспрессия на эндотелиоцитах, как в артериях, так и венах, активируется свободными радикалами кислорода, тромбином, компонентами комплемента, гистамином, перекисями водорода [27]. Взаимодействие Р-селектин с сиалорованым олигосахаридом, который находится на поверхности нейтрофильних гранулоцитов и моноцитов, приводит к адгезии последних на поверхности эндотелия [24-27]. Источником L-селектина есть мононуклеары, после активации которых происходит смывание последних с активацией лимфоцитов и моноцитов, а их органом мишенью есть периферические лимфатические узлы [4]. Высвобождение Купферовскими клетками в условиях гипоксии провоспалительных цитокинов IL-1, IL-8, a-фактора некроза опухоли [3,31], вызывает экспрессию на эндотелий Е-селектина, который, кроме стимуляции адгезии лейкоцитов к эндотелию, оказывает содействие слипанию тромбоцитов с нейтрофильными гранулоцитами в участках повреждения сосудистой стенки, а также активирует процесс взаимодействия моноцитов с эндотелием [10, 13]. Адгезия тромбоцитов приводит к дисбалансу между протромбогенными и антитромбогенными факторами. При контакте тромбоцита с эндотелиоцитом увеличивается его тромбогенный потенциал, который усиливается также за счет высвобождения тканевого тромбопластина [31].

Таким образом, как уже упоминалось ранее, наличие факторов риска у пациентов механической желтухи, способствует прогрессированию эндотелиальной дисфункции и могут иметь множество нежелательных эффектов, в том числе печеночно-клеточной недостаточности.

При механической желтухе нарастает давление в желчных капиллярах, нарушается микроциркуляция клеток печени, что приводит к оксидантному стрессу. Патогенез поражения печеночных клеток при синдроме механической желтухи с проявлением желчной гипертензии и высоких показателях билирубина приводит к повреждению мембран гепатоцитов, секреции Куперовскими клетками провоспалительных цитокинов, трансформации и повреждении эндотелиальных клеток. Нарушение выделения основных компонентов желчи в печеночные протоки при механической желтухе оказывает токсическое действие на гепатоциты с нарушением их функции и ведет к изменению свойств и структуры микроциркуляции в печени. Оксидантному стрессу принадлежит также ключевая роль в инициации повреждения эндотелия. Свободному радикальному окислению наиболее подвержены липопротеиды низкой плотности. Окисленные липопротеиды повреждают сосудистую стенку, обуславливают развитие эндотелиальной дисфункции и нарушения микроциркуляции $[6,8,13]$.

\section{Зак^ючение}

Таким образом, доказано, что в патогенезе синдрома механической желтухи и печеночной недостаточности, в частности, особое место занимает эндотелиальная дисфункция. Основные причины развития эндотелиальной дисфункции при синдроме механической желтухи многообразны и связаны главным образом с длительностью существования билиарной гипертензии с развитием оксидантного стресса, снижением образования оксида азота, повышением синтеза эндотелина, увеличением экспрессии на поверхности эндотелиальных клеток АФК и нарушением целостности эндотелиальной выстелки.

Итак, дисфункция эндотелия при синдроме механической желтухи можно рассмотреть, как дисбаланс между вазодилатирующими и вазоконстрикторными факторами в сторону усиления вазоконстрикции.

Желчная гипертензия оказывает содействие ишемии печени, а это в свою очередь приводит как к эндотелиальным сдвигам, так и к нарушению функции гепатоцитов. Причем при увеличении билиарной гипертензии и продолжительности желтушного периода нарастают и деконструктивные изменения в печени, продолжающаяся ишемия характеризуется ростом билиарной гипертензии, которые приводят к гипоксии ткани печени. Состояние гипоксии вызывает деструктивный сдвиг и дисфункцию эндотелия. Эндотелиальные сдвиги приводят к адгезии тромбоцитов и моноцитов, и миграции их к гепатоцитам. Продолжающаяся гипоксия понижает обменные процессы в гепатоцитах, что приводит к их разрушению. Причем глубина поражений в печени зависит от продолжительности механической желтухи.

\section{Выво $\triangle$}

1. Среди основных факторов развития печеночной недостаточности при механической желтухе является длительность билиарной гипертензии, степень нарушения портального кровотока, эн- 
дотелиальная дисфункция с последующим нарушением морфологии печени.

2. Поиски и изучение основных механизмов нарушения эндотелиальной дисфункции при меха- нической желтухе могут быть перспективным направлением современной гепатологии для прогнозирования и профилактики печеночной недостаточности.

\section{ЛИТЕРАТУРА}

1. Афонасьева Т. Н. Эндотелиальная дисфункция. Возможности ранней диагностики // Здоровье и образование в XXI веке. 2016. Т. 18, № 11. С. 101-104.

2. Беляева А.Н., Козлов С. А., Беляев С. А. Функциональные и морфологические нарушения печени при остром обурационном холестазе и их коррекция (экспериментальное исследование) // Анналы хирургической гепатологии. 2014. № 4. С. 10-15.

3. Васина Л.В., Петрищев Н. Н., Власов Т. Д. Эндотелиальная дисфункция и ее основные маркеры // Регионарное кровообращение и микроциркуляция. 2017. T. 16, № 1. C. 4-15.

4. Воробьева Е.Н., Воробьев Р. И., Шарлаева Е. А., Фомичева М. Л., Соколова Г. Г., Казызаева А. С., Батанина И. А. Дисфункция эндотелия при сердечно-сосудистых заболеваниях: факторы риска, методы диагностики и коррекции // Acta Biologica Sibirica. 2016. Т. 2, № 1. С. 21-40.

5. Гальперин Э.И., Веттев П.С. Руководство по хирургии желчных путей: Видар-М, 2006. 568 с.

6. Гальперин Э.Н., Момукова 0. Н. Классификация тяжести механической желтухи // Хирургия. 2014 № 1. С. 5-9.

7. Гаюров У.Х., Курбанов К. М., Махмадов Ф. Н. Патогенез и лечение дисфункции эндотелия при гнойном холангите // Вестник Авиценны. 2014 . № 4. С. $38-43$.

8. Герасимов А. А. Последние достижения в коррекции функционального состояния эндотелия // Современные проблемы науки и образования. 2015. № 3. C. 11-15.

9. Рубцов Г.К., Безручко Н. В., Емельянчик С. В., Зиматкин С. М. Нарушение окислительной модификации белков и липидов в мониторинге внутрипеченочного и внепеченочного холестаза: пути изучения и диагностики // Вестник ТвГУ. Серия «Биология и экология». 2015. № 2. С. 36-47.

10. Степанова Т.В., Иванов А. Н., Попыхова э. Б., Лагутина Д. Д. Молекулярные маркеры эндотелиальной дисфункции // Современные проблемы науки и образования. 2019. № 1. С. 1-9.

11. Тарасенко С.В., Натальский А. А., Луньков И. А. К вопросу о патогенезе и классификации печеночной недостаточности // Вестник экспериментальной и клинической хирургии. 2017. № 3. С. 286-292.

12. Феоктистова В.С., Вавилова Т. В., Сироткина О. В., Болдуева С. А., Гайковая Л. Б., Леоннова И. А., Ласковец А. Б., Ермаков А. И. Новый подход к оценке дисфункции эндотелия: определение количества циркулирующих эндотелиальных клеток методом проточной цитометрии // Клиническая лабораторная диагностика. 2015. № 4. С. 23-39.

13. Ходосовский М. Н. Коррекция окислительных повреждений при синдроме ишемии реперфузии печени // Журнал ГрГмУ. 2016. № 4. С. 20 -25.

14. Щекотова А. П. Динамика показателей эндотелиальной дисфункции у больных с заболеванием гепатобилиарной системы в процессе лечения // Фундаментальное исследование. 2013. Т. 2, № 5. С. 451-453.

15. Щекотова А. П. Дисфункция и повреждение эндотелия при гепатобилиарной патологии // Уральский медицинский журнал. 2010. Т. 66, № 1. С. 96-99.

16. Щекотова А.П. Состояние эндотелия при желчнокаменной болезни // Актуальные вопросы хирургии: материалы краевой научно-практической конференции, посвященной 90-летию кафедры общей хирургии ПГМА им. Е. А. Вагнера. Пермь, 2011. С. 292-296.

17. Bykov M.L., Basov A. A. Change of parameters in prooxidant-antioxidant bile system in patients with the obstruction of bile-excreting ducts // Medical news of North Caucasus. 2015. V. 2, No 10. P. 131-135.

18. Daiber A., Steven S., Webe A., Shuraev V.V., Muzykantov V. R., Laher I., Li H., Lamas S., Munzel T. Targeting vascular (endothelial) dysfunction // British J. Pharm. 2017. V. 174. P. 1591-1619.

19. Dvorak H. V. Vascular permeability factor (vascular endothelial factor a critical cytokine in tumor angiogenesis and a potential target for diagnosis and therapy) // J. Clin. Med. 2002. V.20. P. 4368-4380.

20. Eras P., Sherlock P. Hepatic coma secondary to metastatic liver disease // Ann. Intern. Med.1971. V. 74 (4). P. 581-3.

21. Giles L.V., Tebbutt S. J., Carlsten C., Koehle M. S., The effect of low and high-intensity cycling in diesel exhaust on flow-mediated dilation, circulating N0x, endothelin-1 and blood pressure. PLOS ONE. 2018. V. 13(2). P. 192-419.

22. Horvatis T., Trauner M., Fuhrmann V. Hypoxic liver injury and cholestasis // Curr. Opin. Crit. Care. 2013. V. 19. P. 128-132.

23. Jay Dcwcet. Multiple organ dysfunction syndrome. Scientific American Surgery 06/2015 Critical Care 2015 // Decker Intellectual Properties D0 10.2310/7800.2160. 2003. V. 17. P. 369-381.

24. Kobashi-Margain R.A., Gavilanes-Espinar J.G., Gutierrez-Grobe Y. Albumin dialysis with molecular adsorbent recirculating system (MARS) for the treatment of hepatic encephalopathy in liver failure //Ann. Hepatol. 2011. № 5. P. 70-76.

25. Kora S.A., Doddamani G. B., Doddamani U., Subacute Hepatic Failure // J. Clin. Diagn. Res. 2011. V. 5, № 1. P. 134-137.

26. Liu H.M., Wang X. B., Zeng H. Survival analysis of short-term prognosis of patients with HBV-related acute-on-chronic liver failure // Zhonghua Yi Xue Za Zhi. 2012. V. 92 , No 1. P. 21-24.

27. Marshall J. C. Measuring organ dysfunction in the intensive care unit. Why and how? // Can. J. Anesth. 2005. V. 52, № 3. P. 224-230.

28. McCuskey R. S. The Hepatic Microvascular System in Health and Its Response to Toxicants // The anatomical record. 2008. No 291. P. 661-671.

29. Mochida S., Takikawa Y., Nakayama N. Diagnostic criteria of acute liver failure // Hepatol. Res. 2011. V. 41, № 9. P. 805-812. 
30. Raurich J.M., Perez 0., Llompart-Pou J.A., et al. Incidence and outcome of ischemic hepatitis complicating septic shock // Hepatol Rea. 2009. V. 34. P. 700-705.

31. Sass D.A., Shakil A. O. Fulminant hepatic failure // Liver Transpl. 2005. V. 11, № 6. P. 594-605.

32. Sundaram V., Shaikh 0. S. Acute liver failure: current practice and recent advances // Gastroenterol. Clin. North Am. 2011. V. 40, No 3. P. $523-539$.

33. Storch A.S., De Mattos J. D., Alves R., Galdino I. Dos S., Rocha N. M. Methods of Endothelial Function Assessment: Description and Applicaions // Int. J. Cardiovasc Sci. 2017. V. 30, No 3. P. 262-273.

34. Teixeira B.C., Lopes A. L., Macedo R. C., Correa C. S., Ramis T. R., Ribeiro J. L., Reischak — Oliveira A. Inflammatory markers, endothelial function and cardiovascular risk // J. Vasc. Bras. 2014. V. 13, No 2. P. 108-115.

35. Zafrmi E.S., Ledercq B., Vemant J. R., Pinaudeau Y., Chomette G., Dhumeaux D. Massive blastic infiltration of the liver a cause of fulminant hepatic failure // Hepatology. 1983.3(3). P. 428-32.

с М Магомедов Хасае Магомедалиевич ( hasai2014@mail.ru ).

Журнал «Современная наука: актуальные проблемы теории и практики»

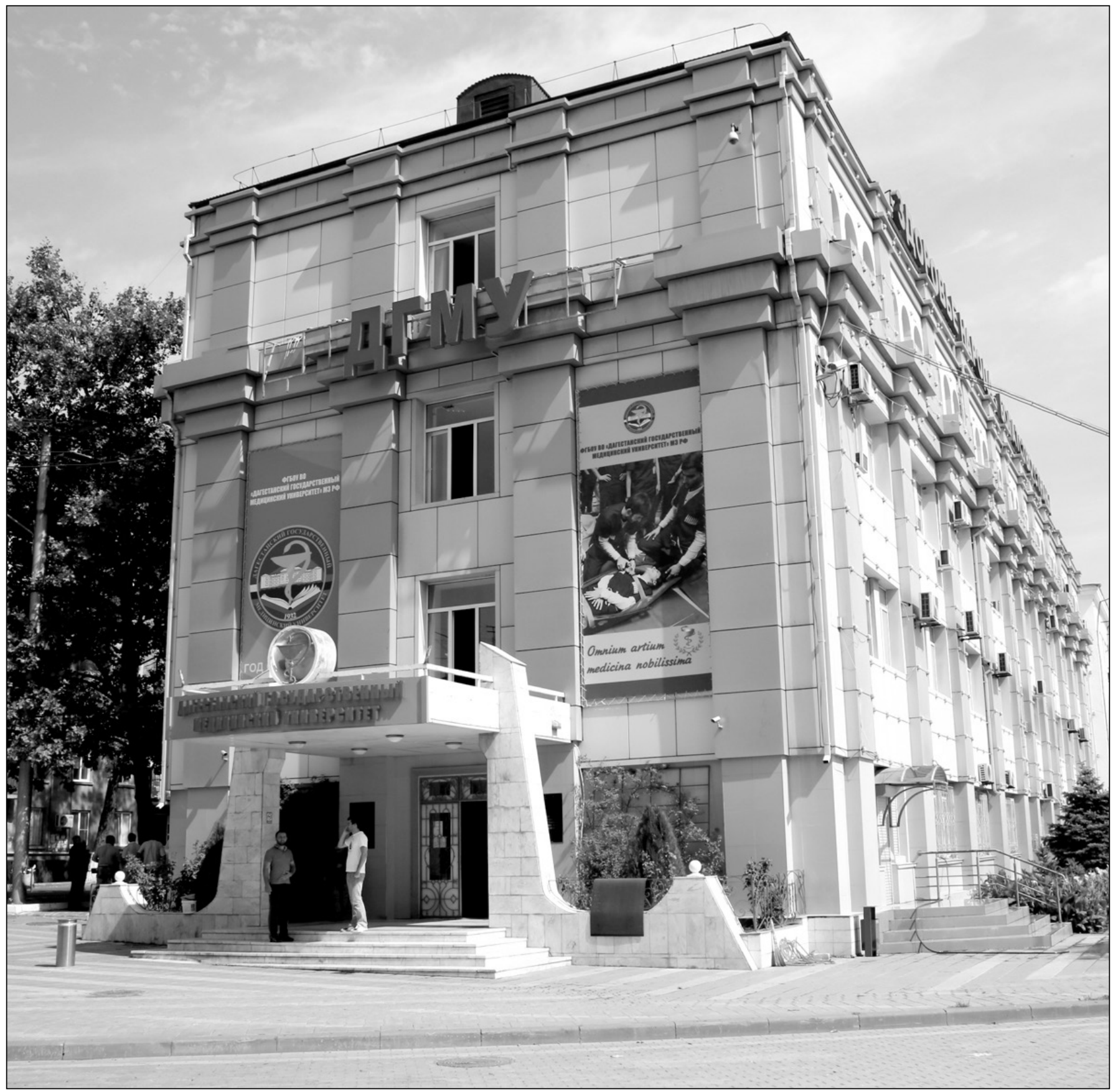

